University of Vermont

UVM ScholarWorks

$9-25-2020$

\title{
Approaches to interdisciplinary mixed methods research in land change science and environmental management
}

\author{
Eva Kinnebrew \\ University of Vermont, ekinnebr@uvm.edu \\ Elizabeth Shoffner \\ Department of Geography, University of Washington \\ Aldo Farah-Pérez \\ Department of Earth and Environment, Florida International University \\ Megan Mills-Novoa \\ School of Geography \& Development, University of Arizona \\ Katherine Siegel \\ Department of Environmental Science, Policy, \& Management, University of California-Berkeley
}

Follow this and additional works at: https://scholarworks.uvm.edu/gund-journal-publications

Part of the Climate Commons

\section{Recommended Citation \\ Kinnebrew, E., Shoffner, E., Farah-Pérez, A., Mills-Novoa, M., Siegel, K., 2021. Approaches to interdisciplinary mixed methods research in land-change science and environmental management. Conservation Biology. 35(1):130-141. https://doi.org/10.1111/cobi.13642}

This Article is brought to you for free and open access by the Collections at UVM ScholarWorks. It has been accepted for inclusion in Peer-Reviewed Studies by an authorized administrator of UVM ScholarWorks. For more information, please contact scholarworks@uvm.edu. 


\section{Approaches to interdisciplinary mixed methods research in land change science and}

environmental management

1. Eva Kinnebrew: Rubenstein School of Environment and Natural Resources and Gund Institute for Environment, University of Vermont, 210 Colchester Ave, Burlington, Vermont 05405, USA, email ekinnebr@uvm.edu

2. Elizabeth Shoffner: Department of Geography, University of Washington, Smith Hall, 408 Skagit Ln, Seattle, Washington 98195, USA

3. Aldo Farah-Pérez: Department of Earth and Environment, Florida International University, Miami, 11200 SW 8th Street, AHC-5 360, Miami, Florida 33199, USA

4. Megan Mills-Novoa: School of Geography \& Development, University of Arizona, 1064 E Lowell St, Tucson, Arizona 85719, USA

5. Katherine Siegel: Department of Environmental Science, Policy, \& Management, University of California-Berkeley, Mulford Hall, 130 Hilgard Way, Berkeley, California 94720, USA

Running head: Mixed-methods approaches

Keywords: Qualitative and quantitative methods, data relationships, integration, iteration, socio-environmental research Article impact statement: Articles with mixed methods fit into five methodological types in which there is limited integration and iteration among methods. 


\begin{abstract}
Combining qualitative and quantitative methods and data is crucial to understanding the complex dynamics and often interdisciplinary nature of conservation. Many conservation scientists use mixed methods, but there are a variety of mixed methods approaches, a lack of shared vocabulary, and few methodological frameworks. We reviewed articles from 2 conservationrelated fields that often incorporate qualitative and quantitative methods: land-change science $(n=16)$ and environmental management $(n=16)$. We examined how authors of these studies approached mixed-methods research by coding key methodological characteristics, including relationships between method objectives, extent of integration, iterative interactions between methods, and justification for use of mixed methods. Using these characteristics, we created a typology with the goal of improving understanding of how researchers studying land-change science and environmental management approach interdisciplinary mixed methods research. We found 5 types of mixed methods approaches, which we termed simple nested, informed nested, simple parallel, unidirectional synthesis, and bidirectional synthesis. Methods and data sources were often used to address different research questions within a project, and only around half of the reviewed papers methodologically integrated different forms of data. Most authors used one method to inform the other rather than both informing one another. Very few articles used methodological iteration. Each methodological type has certain epistemological implications, such as the disciplinary reach of the research and the capacity for knowledge creation through the exchange of information between distinct methodologies. To exemplify a research design that can lead to multi-dimensional knowledge production, we provide a methodological framework that bidirectionally integrates and iterates qualitative and quantitative methods.
\end{abstract}




\section{Introduction}

The complex socioenvironmental dynamics of conservation problems highlight the need for approaches that bridge different knowledge forms (Liu et al. 2007; Wolfram et al. 2013). In particular, combining quantitative and qualitative data from the natural and social sciences allows one to interrogate not only quantitatively measurable processes, but also how these processes are interpreted or perceived - and therefore acted upon - by humans. For example, in the field of land-change science, traditional land-use change models rely on quantitative approaches and are limited to factors that can be geolocated or spatialized (Arima et al. 2011; Lawler et al. 2014). Combining qualitative data with quantitative spatial data can contextualize or aid the description of land-use patterns while corroborating or grounding narratives in space. Broadly, interdisciplinary, mixed methods research results in a more holistic view of complex problems and highlights the diverse factors critical to making research socially effective, which can facilitate more effective political and social interventions (Palmer 2012; Bennett et al. 2017).

However, one must look beyond just the inclusion of qualitative and quantitative methods and consider how they are used and combined in the methodological process. Among the many studies that bridge different knowledge forms, methodological approaches to mixed methods research vary widely. Some researchers use methods side by side to complement each other or triangulate results, whereas others take a more integrative approach, transferring or communicating data between methods to produce a more synthesized final result (Olsen 2004; Cheong et al. 2012). While there is no best way to conduct mixed methods research, it is important to understand that the relationships established between qualitative and quantitative methods in research design are epistemological choices that shape both the conceptualization of 
the object of study and the interpretation of results (Onwuegbuzie \& Hitchcock 2015) and have implications for understanding of conservation issues.

One major challenge of mixed method research in conservation science is the lack of shared vocabulary and methodological frameworks (Brandt et al. 2013; Elsawah et al. 2020). This may cause researchers to make unintentional or uncertain methodological choices without understanding the methodological possibilities, practical ways to bridge methodologies, or the epistemological implications of research choices. Inconsistencies in vocabulary can also cause researchers to miscommunicate methodological choices (Brandt et al. 2013). For instance, some researchers presenting empirical findings use the word integrate to imply that multiple methods are used (Gonzalez et al. 2009; Mehring \& Stoll-Kleeman 2011), whereas theoretical approaches to mixed methods often use integrate to specifically imply synthesis or a hand-off of data between methods (Bryman 2007; Bazeley 2010; Vogl 2019). A more standardized characterization of approaches to mixed methods research may guide researchers in designing and explicitly communicating their research.

Creating a typology (i.e., a categorization) of mixed methods approaches in conservation is a key way to elucidate possible methodological structures and the characteristics that differentiate them. Among the typologies that have been developed, many focus on a particular dimension of mixed methods approaches. For example, some existing typologies focus on the degree to which integration occurs, a principal difference among mixed methods studies. Vogl (2019) discusses the difference between data combination and integration, noting that when data are combined, the elements are independent, whereas integrative methods create a "joint product" and each source of data "aims for the same research objective" (p. 537). Similar differentiations (with slightly different terminology) occur in Cheong et al. (2012) for 
complementarity" and integration designs and in Yin (2006) for isolated and integrated (remainder not marked) designs. Other axes of differentiation among mixed methods approaches include the number of methodological phases in a project (i.e. branches or iterations), the order in which each method is implemented, the established hierarchy (priority) between methods, and the particular function of each method within the broader study (Teddlie \& Tashakkori 2006; Creswell \& Plano Clark 2017). A classic typology by Greene et al. (1989) is often used to characterize the functions of mixed methods designs and includes triangulation, complementarity, development, initiation, and expansion types. In triangulation, for example, methods are used to narrow in on a single objective, and in expansion 1 method is used to add additional depth to the research question.

Previous typologies lay important groundwork for understanding mixed methods approaches, but lack direct applicability and usefulness to conservation. Much of the mixed methods literature deals with using qualitative and quantitative methods to collect data from human subjects (i.e. Bryman 2007; Vogl 2019), whereas in conservation science, mixed methods research often bridges quantitative data from natural science with qualitative data from social science. Interdisciplinary mixed methods research presents additional complexity in integrating data because the data originate from two or more disciplinary frameworks. Therefore, to best understand and guide research in conservation, we specifically built our typology from interdisciplinary mixed methods research. Our review is additionally novel in that we examined the trends of mixed methods approaches in conservation-related literature, pointing to approaches that are more common and highlighting methodological gaps that remain relatively unexplored. While this study is not an exhaustive review of literature across conservation science (we focused on two specific conservation fields out of many), developing a typology based on 
literature from conservation-related fields allowed us to use topically relevant examples and frameworks. We believe this will radically improve interest, understanding, and application of interdisciplinary mixed methods research among conservation scientists.

We sought to create a guide for interdisciplinary teams of conservation scientists, such as our own, and to respond to broad calls for mixed methods approaches to socio-environmental research (Palmer 2012; McGinnis \& Ostrom 2014). We characterized approaches to mixed methods research with a literature review from two conservation-related fields (land change science and environmental management) to make explicit mixed methods approaches and their epistemological implications. We aimed to identify and explain key methodological characteristics that distinguish approaches; create a typology scheme into which all reviewed articles fit; identify trends in the literature and potential methodological gaps; and suggest an example framework that fills methodological gaps for conservation science, drawing from ongoing collaborative research.

\section{Methods}

\section{Fields of focus}

We conducted a literature review to determine and categorize how authors conducting mixed methods research use and leverage different kinds of data and specifically chose literature from the fields of land change science and environmental management due to their strong connection to conservation issues. Land change science, also called land-use change or land system science, explores the dynamics of land-cover change and human uses of land systems (Turner et al. 2007), which are among the greatest threats to biodiversity conservation globally (Newbold 2015). Environmental management focuses on how humans manage natural resources, 
ecosystems, and other aspects of the environment for conservation and sustainability objectives, encompassing forestry, fisheries science, and other related subfields, and thus is an important solution to many conservation problems (Virapongse et al. 2016).

We chose these fields because they are often studied using both qualitative and quantitative methods. Furthermore, these fields commonly (though not always) utilize different kinds of quantitative data - typically spatial data, such as satellite imagery for land change science, and field-based data for environmental management - which allowed us to assess how different kinds of quantitative data interacted with qualitative data. To ensure that the articles we reviewed fit into the two fields of interest, we checked that the land change science articles addressed spatial aspects of how landscapes transform over time and that the environmental management articles addressed the management of a natural resource (e.g. fish populations, biodiversity, soil, or forests). The boundaries of research fields are sometimes fuzzy, and some articles can fall into several fields. We used two fields of study rather than one to increase robustness of the typology scheme. We developed the typology with land change science and then validated it with environmental management.

There are many additional fields within conservation that might have also been good candidates for this review. By focusing on land change science and environmental management, our results speak most directly to trends and structures in those fields. However, we believe that the methodological structures we identified start an important conversation that is relevant and applicable to other fields.

Also, while some interdisciplinary teams in conservation publish their research in several articles, separating quantitative and qualitative methods from a single project or using different methods in future articles to expand knowledge, we intentionally looked at how methods are 
used in single articles in our review. Aggregating and communicating mixed methods research in an individual published output is essential to describing and interpreting the breadth of this research and its integrated contributions (Yin 2006).

\section{Literature search and exclusion process}

We first identified a selection of mixed methods articles in land change science through a series of keyword searches in Web of Science, which we carried out between August-November 2019. We searched within all available years (1950-2020), used all available databases, and used the "topic" keyword search option, which searches article titles, abstracts, author keywords, and Keywords Plus (keywords identified by an algorithm that searches articles' works cited). We used the keywords "mixed methods OR interdisciplinary OR multidisciplinary," "qualitative OR discourse," "quantitative AND qualitative," "conservation OR environment" and field-specific keywords, including "LULC OR land use OR land change". We reviewed all articles that matched our search criteria, or in the case that our search yielded many hundreds of articles, we sorted articles by relevance in Web of Science and reviewed the top 300 most relevant articles. Relevance in Web of Science is determined by how many search terms are present in the articles, with title and author keywords weighted slightly higher than the abstract and Keywords Plus fields. For each combination of keywords, we undertook two review phases to test the resulting articles for relevance. First, we conducted a coarse preliminary review within Web of Science, where we read article titles and abstracts and downloaded only the articles that met our inclusion criteria, described below. We then closely reviewed all downloaded articles by reading their introductions, methods, and results sections to yield a final set of relevant articles for our analysis. 
To meet our inclusion criteria, an article had to include data on both the social and natural components of the study system (i.e. be interdisciplinary in scope) and apply both quantitative and qualitative methodologies (i.e. have mixed methods). Most of the articles we reviewed did not fulfill both of our inclusion criteria. Some articles that we excluded used mixed methods, but only included social data. A large number of other articles that we excluded were interdisciplinary but only included quantitative methods or data. We specifically considered data qualitative if they were both collected with a qualitative method (e.g., interviews, focus groups, archival research) and analyzed qualitatively (i.e., discourse analysis). Studies for which qualitative data was entirely converted to quantitative data (e.g. extracting categorical data like plot size or crop type from interviews) were excluded. Social science surveys that were used to gather quantitative data also did not meet our inclusion criteria. We excluded articles in which methods were not described sufficiently for categorization. For most articles in the preliminary review process, it was clear whether the article was relevant, and only one of us read each paper. For articles whose relevance was less clear (around 20\%), 2 of us read the paper and then discussed and jointly decided on the article's relevance.

For the land change science articles, our preliminary review yielded 45 potentially relevant articles. After excluding all nonrelevant land change science articles through our detailed secondary review, we had a sample of 16 relevant articles.

We then expanded our literature search to include articles in the field of environmental management. In February 2020, we performed a second set of keyword searches in Web of Science with the same set of keywords as for the land change science article search, replacing land change science keywords "LULC OR land use OR land change" with management. Using the same inclusion criteria described above, we identified 43 potentially relevant articles in our 
preliminary review and ultimately selected 16 relevant articles after our detailed secondary review.

\section{Coding scheme and typology generation}

We created a coding scheme to categorize and differentiate mixed methods approaches, and guide the creation and application of a typology. This coding scheme was developed by E.K. and E.S., a quantitative natural scientist and a qualitative social scientist, respectively, and was based off a careful review of a random subset of around 15 land change science articles (of the 45 potentially relevant articles, prior to the final exclusion). We took a hybrid inductive-deductive approach in which we identified emergent characteristics from articles but were guided by previous frameworks that list key differentiating features among mixed methods approaches (i.e. Greene et al. 1989; Creswell et al. 2006; Teddlie \& Tashakkori 2006; Vogl 2019). Among these preestablished coding themes, we identified and revised themes that best differentiated the methodological approaches in our sample articles. The resulting coding scheme included the following points: relationship of method objectives, extent of integration, iterative nature of interactions between methods, and justification for using mixed methods (Appendix S1 \& S2).

The relationship of method objectives is an adaption and distillation of the five types in the typology from Greene et al. (1989). Their schema includes development (using one method to inform sampling protocol of the other), expansion (using methods for different inquiry components), triangulation (using multiple methods to strengthen the validity of the findings), complementarity (expanding knowledge by using methods to address often overlapping but sometimes distinct aspects of a single question), and initiation (seeking contradictions by analyzing data from different frameworks). These types by Greene et al. (1989) take into account 
authors' intentions or assumptions in using different methods; but intentions and assumptions are not always stated or easily assumed. Therefore, we found it most straightforward and within scope to focus on methodological structures. More precisely, we distilled these five types into two categories: methods are used to address different objectives (i.e. development and expansion) -- which we term nested -- and methods are used to address similar objectives (i.e. triangulation, complementarity, and initiation) -- which we term parallel.

We describe methodological integration as how methodologies interact to draw from, inform, and shape one another. Bazeley (2010, pg. 432) provides a useful note on integrated data: "the elements cannot be treated separately again." To be coded as having integration, we required a direct hand-off of information (data) from one methodology to the other: e.g., qualitative focus groups informing modeling parameters (Cohn et al. 2016); or quantitative findings used to direct the topic of interviews (Williams \& Kramer 2019). Articles that only linked qualitative and quantitative methods in the conceptualization stage of the study (i.e. objectives setting), for example, by grounding methods in the same geographic space, were not considered as engaging in integration (e.g. Richmond et al. 2015). We noted the extent of integration, including whether only one method informed the other (unidirectional) or whether they informed one another (bidirectional). We also noted whether articles iterated methodological integration. We define iteration as information repeatedly passed back and forth between the methodologies to bolster and strengthen the creation of knowledge or repetitively reinform the other methodology (Knigge \& Cope 2006; Onwuegbuzie \& Hitchcock 2015).

Finally, we categorized the methodological justifications of sampled articles, as these often (though not always) implicitly summarized the typology. Justifications also indicated how the authors conceived of the epistemological implications of their research. 
Based on the discrete coding responses of the 15 land change science articles with which we created the coding scheme, four main types of methodological approaches emerged. Following a final exclusion process of the 45 potentially relevant land change science articles, we fully read the final 16 articles, completed the table that characterized them according to the coding scheme, and categorized them in one of the four types in our typology. All articles were

read at least twice by two different authors. In the case of disagreement about where to locate an article within the typology, a third author read the article and validated the type.

We then tested our typology with relevant literature from the field of environmental management. Two to three authors read and analyzed these articles according to our coding scheme and classified them using the typology created for the land change science articles. Through this process, we revised and refined the typology scheme, including one additional category that emerged as prominent in this body of literature. We then returned to the land change science articles and reclassified them based on the refined typology.

\section{Results}

\section{Mixed Methods Types}

In the land change science articles, we identified four main types of mixed methods: simple nested, simple parallel, unidirectional synthesis, and bidirectional synthesis. An additional type emerged in the management articles: informed nested (Table 1). While there are many ways that articles differed in how they used qualitative and quantitative methodologies, we found that articles were best differentiated along two main axes: relationship between method objectives (i.e., the role of each method in answering research questions) and integration between methods (i.e., existence of a flow of information between methods). We therefore used these two axes of 
differentiation to develop our typology. Our typology can be described using a matrix (Figure 1), in which the vertical axis categorizes the relationship between method objectives (nested or parallel) and the horizontal axis categorizes the extent of integration (none, unidirectional, bidirectional). For instance, in the simple nested type, methods were used to address different study objectives (nested structure) and there was no integration between methods occurs, whereas in the unidirectional synthesis type, methods were used to address similar objectives (parallel structure) and there was unidirectional integration between methods.

\section{Relationships between method objectives}

The relationship between method objectives, as we described it, revealed the role of qualitative and quantitative methods in addressing research questions. Important questions included: what is the purpose of each method and do those purposes match, or, if not, how do they relate? For example, if the purpose of qualitative data was to identify sampling sites, whereas the purpose of quantitative data was to determine fish population dynamics (Adams et al. 2019), then the purpose of each method was different, and we considered this relationship nested (named to reflect the contingent, sequential, or uneven uses of the methods). If the purpose of both the qualitative and quantitative data was to understand the effect of an event, such as a temporary fishing closure (Richmond et al. 2015), then the purposes matched, and we considered this relationship parallel (named to reflect concurrent and sometimes simultaneous use of methods). If the study objective was inherently tied to the integration of methods, we also considered the relationship parallel, and these articles were placed in the unidirectional or bidirectional synthesis type. 
We found that many sampled articles had a nested relationship between quantitative and qualitative methods (simple nested or informed nested types). These articles often used quantitative spatial or ecological data to describe a state (the "what") and qualitative data to explain dynamics (the "why"). For example, Qasim et al. (2013) used quantitative remote sensing data to determine the "extent and type of land use changes" and qualitative interview data for "detecting and analyzing the drivers of change" (see Table 1 for more examples).

Simple and informed nested designs also often had a hierarchy of data (a dominance of one method over the other). Data hierarchies were usually clear in the methods section of the articles, where the description of the non-dominant method was relatively short and less rigorous. For example, in one article there was no description of how qualitative documents were chosen, collected, or analyzed (Batalha Roque et al. 2019); in another, there was little explanation of remote-sensing methods (Hruska 2019). Interestingly, hierarchies occurred both ways, with no clear trend indicating that one methodology was more often dominant over the other.

The other general relationship between article methods, parallel, was often used to assess phenomena through natural and social science lenses, for example by using both quantitative modeling and qualitative interviews to determine drivers of land-use change (Kleemann et al. 2017). The simple parallel, unidirectional synthesis, and bidirectional synthesis typologies all were characterized by this parallel relationship, although they differed in their extent of integration (described below). It was less common (though not impossible) for articles with parallel designs to have a hierarchy of data, perhaps because equally rigorous methods help effectively triangulate results or integrate data. 


\section{Extent of integration and flow of information between methods}

In around half of the reviewed articles, there was no integration between methods, and these articles were categorized either as simple nested or simple parallel. In articles that had integration, extents of integration differed. In some articles, one methodology was used to inform the other, which we termed unidirectional integration. For example, unidirectional integration occurred when expert knowledge informed field sites for quantitative data collection, but no part of the quantitative method informed qualitative methods or data (e.g., Adams et al. 2019). These articles were categorized as informed nested if the relationship between methods was nested or unidirectional synthesis if the relationship between methods was parallel (Figure 1, Table 1). Integration was bidirectional when each methodology informed the other. An example of bidirectional integration included a research design in which content analysis of peer-reviewed literature was used to determine preliminary drivers of land-use change and was applied in quantitative models and then model results were assessed and validated by focus groups (Kong et al. 2019). Articles with bidirectional integration were classified into the bidirectional synthesis type.

The extent of integration in articles was usually evident in the structure of articles. Articles without integration often had distinct quantitative and qualitative sections in the methods and results. Articles that included integration more often included sections that explained the integration of the methodologies; these articles less commonly separated methods and results into disciplinary headings (e.g., these articles tended to structure results according to thematic headers, such as "Case Study A," rather than methods-oriented headers, such as "Remote Sensing" and "Interviews"). 
Some articles that integrated methodologies also used iteration. Iteration was frequently a characteristic of a coproduction model of scientific inquiry, where stakeholders were included in the knowledge production process, often by providing feedback on successive stages of the research process (e.g. Prokopy et al. 2017). However, our use of the term iteration specifically refers to repeated data flows (integration) between qualitative and quantitative methods, rather than information flows between actors. Iteration of methodological integration as we understand it occurred only in coproduction models if qualitative data from stakeholders were incorporated as data.

An example of an iterative framework involved using qualitative data to repetitively assess and improve quantitative models (Polhill et al. 2010). In this case, data from the quantitative method informed the qualitative process (via researchers asking participants to react to and assess model outcomes), and vice versa (the model was revised according to participant answers). The iterative process may be repeated several times until a satisfactory end is reached. Other authors used a variety of methods at each point of iteration (e.g. interviews inform quantitative variables; after quantitative analysis is done, results are validated by a focus group), as in Murgue et al. (2016:352), who described their methodology "Repeatedly, generic [quantitative] knowledge was used to help elicit local [qualitative] knowledge, and local knowledge were used to clarify, question and supplement the generic databases available." This showed a repeated bidirectional feedback between qualitative and quantitative methods, which ultimately allowed for a dynamic incorporation of a variety of information.

\section{Justification for Utilizing Mixed Methods}


Some authors provided only a practical justification of methods, simply explaining the purpose of mixed methods in a discussion of their methods or results. Articles with nested structures typically used words such as "to better understand" when describing why a second method was incorporated. For example, Taylor et al. $(2016 ; 294)$ had an informed nested design and said, "[the] linking of sources provides better explanations of change observed in land-cover from satellites and also permits spatial location of social data." This justification pointed to the general value of mixed methods, but provided little specificity as to how or why this better understanding was achieved.

Studies with parallel structures often used words such as "compare," "triangulate," and "complementary" to explain the practical relationship between their methods. Some articles with parallel structures also included statements indicating they needed another method to improve or fill out knowledge. For example, Burr et al. (2018: 1127) justified using qualitative data by noting that quantitative "demographics give an incomplete picture of possible factors." Sharma et al. (2016:507) similarly highlighted the need for "a combination of both quantitative and qualitative participatory data to fully comprehend the range of factors leading to perceived differences in land cover," indicating the use of a second method to expand knowledge.

We also found two categories of broader justifications of methodological decisions: theory-based (knowledge-oriented) and value-based (action-oriented) justifications. Theorybased justifications called on interdisciplinary or mixed methods theory to argue that their methodological choices produce more accurate scientific knowledge about a complex reality. For example, Gonzalez et al. (2009, pg. 3), a simple nested study, cited critical realism theory, noting, "we assumed that the analysis, integrating different forms of knowledge, would allow us to be closer to ontological reality." Murgue et al. (2016, pg. 340), a bidirectional synthesis study 
similarly noted, "[t]he central idea is that looking at the same object from different angles better represents its reality." Other authors more directly cited the need for mixed methods to address their research questions. Monroy-Sais et al. (2016, pg. 1150), an informed nested study, stated, "[t]he nature of our research problem is clearly interdisciplinary and therefore had to be resolved using more than one single method."

Value-based justifications made the normative claim that adding a second method (or multiple methods) produces better science to more appropriately inform action, outreach, and policy. For instance, Nugroho et al. (2018, pg. 510), a unidirectional synthesis study, noted that "by combining spatial models with GIS and field surveys to develop scenarios that are as realistic as possible, we can provide better evidence to help decision-makers and other stakeholders." Another author of a unidirectional synthesis study noted, "Many of these studies fail to take herders' actual management into account, make unfounded assumptions about herders' knowledge and practices, and thus lead to untenable policy prescriptions" (Hopping et al. 2018, pg. 147), highlighting the shortcomings of other related research and the benefit of their own mixed methods design.

The diversity of justifications we found reflects that interdisciplinary and mixed method researchers have very different conceptions of the use and value of incorporating qualitative and quantitative methodologies. In citing value-based or theory-based justifications, authors reflected an understanding of the epistemological considerations of their research and indicated the benefit of mixed methods or integrative research. Interestingly, however, some authors who cited valuebased and theory-based justifications did not use methodological approaches, such as integration, that bridge disciplinary divides and reflect mismatches between intention and action (or theory and practice). 


\section{Trends in each body of literature}

Both land change science and environmental management articles showed similar broad trends in approaches to mixing qualitative and quantitative methods. In both fields, there were approximately equal numbers of articles with nested structures versus parallel structures, though integration between methods was slightly more common in environmental management (69\% of articles) than in land change science articles (44\% of articles) (Appendix S2). In both fields, bidirectional integration and iteration were rare. Looking at both fields together, we found that integration of methods has become more common in recent years; no articles integrated methods from 2008 to 2011 , versus $50 \%$ that did so in 2012 to 2015 and $71 \%$ that did so in 2016 to 2019 (Appendix S4). Most land change science articles used satellite imagery or other spatial data, whereas environmental management articles commonly used samples collected through fieldwork (e.g., took soil samples or conducted vegetation surveys). Interviews were the most common qualitative method for both fields.

\section{Discussion}

\section{Broad value of our typology}

We found that researchers incorporated qualitative and quantitative data within land change science and environmental management in varied and overlapping ways. By employing a largely inductive process informed by knowledge of possible methodological structures, our typology is grounded in how conservation scientists conducted research and is distinct from the work of others who mapped research decisions onto a matrix of pre-existing methodological designs (Teddlie \& Tashakkori 2006; Yin 2006). This process allowed us to identify two key axes of 
differentiation among articles: the relationship between method objectives and the degree of integration. Within the relationship between methods objectives, we also found that categorizing articles as nested or parallel best described distinctions within our sample and revealed a refined way to understand differences between methods' functions, in contrast to the typology by Greene et al. (1989), which listed 5 types to describe method objectives. Additionally, we found that certain combinations of methodological choices were often related (e.g. hierarchy of data and

nested structures). Therefore, our typology not only provides a straightforward way to describe research, but also provides insights into methodological trends, which helps identify the decisions that shape knowledge production.

\section{Epistemological implications of mixed methods approach types}

As the most common type in both fields, simple nested approaches indicated that researchers in land change science and environmental management are often using mixed methods to respond to different research questions with separate objects of study. Greene et al. (1989, pg. 269) similarly found that the purpose of mixed methods most frequently cited by researchers was "to extend the scope, breadth and range of inquiry by using different methods for different inquiry components" (their expansion type). Simple nested studies may remain prevalent in mixed methods research because they avoid many of the challenges associated with pairing data that are methodologically or topically dissimilar (a challenge that may be heightened in interdisciplinary mixed methods research). In some cases, especially where there is a hierarchy of data, simple nested studies may reflect research done by people trained in a dominant method, which include other methods as an accessory, rather than as fundamental to a project. Along these lines, in articles with strong hierarchies of data, the research findings may be situated within a certain 
discipline, limiting the possible value of this research for interdisciplinary knowledge production. However, one important value of simple nested structured studies is that they allow researchers to respond to multiple questions within a single project. For example, simple nested studies can discuss not only the extent, but also the drivers of land-use change (e.g. Jepson et al. 2010; Scales et al. 2011) or assess both resource management trends and stakeholders' perceptions of practices (e.g. Gonzalez et al. 2009; Wittman \& Johnson 2008).

Conversely, simple parallel studies use mixed methods to create two bodies of knowledge that provide multiple (often non-hierarchical) perspectives on the same object of study, with methodological plurality improving validity, diversifying knowledge, or highlighting contrasts between qualitative and quantitative data (Greene et al. 1989). While this type does not engage in integration in the methodological phases, we argue that the parallel structure may be more suited to comparing or mixing results in the interpretation stages of research, which can aid in a more dynamic understanding of the research topic (Vogl 2019). Therefore, it is useful to differentiate between simple nested and simple parallel, our two non-integrative types, because they indicate different possibilities for findings to be synthesized later in the research process.

Our other three other methodological types (informed nested, unidirectional synthesis, and bidirectional synthesis), which make up half of our sample, include methodological integration. However, how integration is achieved is determined by the structural relationship between method objectives. In the informed nested type, the data hand-off between methods often occurred in sequential research phases, such as where quantitative findings on soil erosion inform subsequent interview questions on the perceptions of erosion risk (Blake et al. 2018). Conversely, integration within parallel structured studies (i.e. unidirectional and bidirectional synthesis types) can occur simultaneously and more collaboratively, "facilitat[ing] joint 
learning" of the methods toward a common objective (Christie et al. 2016, pg. 7). Through integration, data analyzed through distinct methods can refine or guide one another, which in itself creates additional data and expands the base of data. This is expressed clearly by the notion in mixed methods research that $1+1=3$; that is, integrating qualitative and quantitative methods results in a research product that has more value than the two parts individually (Fetters \& Freshwater 2015; Vogl 2019).

Finally, iteration was extremely uncommon in our sample. Because iteration by definition necessitates integration, the lack of integration and specifically unidirectional and bidirectional synthesis studies in our sample added to its rareness. Iteration tends to follow an inductive (nonhypothesis-driven) research model, whereby at each iterative phase of research a critical reflection process takes place, determining next steps in the research process (Knigge \& Cope 2006; Yom 2015). Using iteration in conservation research may provide insights because each successive iteration uncovers new patterns and explanations. For example, conducting a focus group that repeatedly responds to and informs a model that simulates impacts of management decisions on wildlife populations may help researchers narrow in on which decision will be both environmentally beneficial and socially acceptable. Therefore, iteration can ignite conversation between research elements, produce increased levels of refinement, and illuminate new dynamics that non-iterative research cannot.

\section{Highlighting and filling research gaps}

Our results highlight two main methodological gaps within our subsample of conversation science. First, with only half of the sampled articles integrating methods (and most doing so unidirectionally), land change science and environmental management seem to have the same 
"integration challenge" that is pervasive throughout mixed methods research (Fetters \& Freshwater 2015; Cheong et al. 2012). It is important to note that methodological integration has increased in recent years (Appendix S4), perhaps spurred by articles that have highlighted a lack of integration (Östlund et al. 2011; Cheong et al. 2012), provided methodological guidance (Vog1 2019), or made calls for increased integration (Palmer 2012; Fetters \& Freshwater 2015). Increasing rates of integration may also reflect the rise and normalization of interdisciplinary conservation graduate programs (Newing 2010). Second, there may be an even bigger "iteration challenge" in mixed methods research; iteration was used in $<10 \%$ of sampled articles. We argue that research with integrative and iterative approaches to combining qualitative and quantitative data could provide new opportunities to understand conservation problems and develop appropriate interventions.

To exemplify how researchers can engage in integration and iteration, we provide here a generalized example of bidirectionally integrated and iterative research that our interdisciplinary team developed to examine land-use change dynamics (Fig. 2; Appendix S1 contains descriptions of how integration and iteration were applied in sampled articles). In this framework, we used a land-cover model that not only input quantitative data, but also incorporated emergent themes and relationships by informing the addition of new variables identified as important in a qualitative analysis of textual data. In turn, significant variables from the land-use model highlight potentially important themes (codes) that structure the qualitative analysis. We iterated methodological integration between quantitative and qualitative methods at two moments in the research process: at the early stage of variable selection and then multiple times at the intermediary stage of land-use model refinement. Our analysis allowed us to not only inspect qualitative or quantitative results, but also to analyze their interactions. For instance, we 
assessed the impacts of integration on model accuracy and found important drivers of land-use change that might not have been recognized otherwise. We believe this framework could be applied to examine other conservation issues to enhance holistic understanding of other complex socio-environmental problems.

We suspect that many researchers, organizations, or funders want to promote and engage in cross-disciplinary collaborations that lead to multi-dimensional knowledge production. While there are still many logistical difficulties to conducting mixed methods and interdisciplinary research, such as structural constraints like time availability and lack of collaboration opportunities, we hope this article will alleviate previous uncertainty regarding how to conduct such research and specifically that our typology will assist researchers in making explicit, intentional decisions and in understanding the epistemological implications of these decisions.

\section{Acknowledgments}

This work was supported by the National Socio-Environmental Synthesis Center (SESYNC) under funding received from the National Science Foundation DBI-1639145. We also thank J. Ochoa for thoughts on an early draft.

\section{Supporting Information}

Additional information is available online in the Supporting Information section at the end of the online article. The authors are solely responsible for the content and functionality of these materials. Queries (other than absence of the material) should be directed to the corresponding author. 


\section{Literature Cited}

Adams AJ, Shenker JM, Jud ZR, Lewis JP, Carey E, Danylchuk AJ. 2019. Identifying prespawning aggregation sites for bonefish (Albula vulpes) in the Bahamas to inform habitat protection and species conservation. Environmental Biology of Fishes 102:159-173.

Arima E, Richards P, Walker R, Caldas MM. 2011. Statistical confirmation of indirect land use change in the Brazilian Amazon. Environmental Research Letters 6:024010.

Batalha Roque MP, Ferreira Neto JA, Lopes de Faria AL, Ferreira FM, Teixeira TH, Coelho LL. 2019. Effectiveness of Arguments Used in the Creation of Protected Areas of Sustainable Use in Brazil: A Case Study from the Atlantic Forest and Cerrado. Sustainability 11:1700.

Bazeley P. 2010. Computer-Assisted Integration of Mixed Methods Data Sources and Analyses. Pages 431-468 SAGE Handbook of Mixed Methods in Social \& Behavioral Research. SAGE Publications, Inc., 2455 Teller Road, Thousand Oaks California 91320 United States. Available from http://methods.sagepub.com/book/sage-handbook-of-mixed-methods-socialbehavioral-research-2e/n18.xml (accessed April 16, 2020).

Bennett NJ et al. 2017. Conservation social science: Understanding and integrating human dimensions to improve conservation. Biological Conservation 205:93-108.

Blake WH et al. 2018. Soil erosion in East Africa: an interdisciplinary approach to realising pastoral land management change. Environmental Research Letters 13:124014.

Brandt P, Ernst A, Gralla F, Luederitz C, Lang DJ, Newig J, Reinert F, Abson DJ, von Wehrden H. 2013. A review of transdisciplinary research in sustainability science. Ecological Economics 92:1-15. Elsevier.

Bryman A. 2007. Barriers to Integrating Quantitative and Qualitative Research. Journal of Mixed Methods Research 1:8-22. 
Burr A, Hall DM, Schaeg N. 2018. The perfect lawn: exploring neighborhood socio-cultural drivers for insect pollinator habitat. Urban Ecosystems 21:1123-1137.

Cheong SM, Brown DG, Kok K, Lopez-Carr D. 2012. Mixed methods in land change research: towards integration. Transactions of the Institute of British Geographers 37:8-12.

Christie ME, Parks M, Mulvaney M. 2016. Gender and local soil knowledge: Linking farmers' perceptions with soil fertility in two villages in the Philippines. Singapore Journal of Tropical Geography 37:6-24.

Cohn AS, Gil J, Berger T, Pellegrina H, Toledo C. 2016. Patterns and processes of pasture to crop conversion in Brazil: Evidence from Mato Grosso State. Land Use Policy 55:108-120.

Creswell JW, Plano Clark VL. 2017. Designing and conducting mixed methods research. Sage publications.

Creswell JW, Shope R, Plano Clark VL, Green DO. 2006. How interpretive qualitative research extends mixed methods research. Research in the Schools 13:1-11.

Elsawah S et al. 2020. Eight grand challenges in socio-environmental systems modeling. SocioEnvironmental Systems Modelling 2:16226-16226.

Fetters MD, Freshwater D. 2015. The $1+1=3$ Integration Challenge. Journal of Mixed Methods Research 9:115-117.

Gonzalez C, Clemente A, Nielsen K, Branquinho C, Santos R. 2009. Human-Nature Relationship in Mediterranean Streams: Integrating Different Types of Knowledge to Improve Water Management. Ecology and Society 14. Available from https://www.ecologyandsociety.org/vol14/iss2/art35/ (accessed February 19, 2020).

Greene JC, Caracelli VJ, Graham WF. 1989. Toward a Conceptual Framework for MixedMethod Evaluation Designs. Educational Evaluation and Policy Analysis 11:255-274. 
Hopping KA, Yeh ET, Gaerrang, Harris RB. 2018. Linking people, pixels, and pastures: A multi-method, interdisciplinary investigation of how rangeland management affects vegetation on the Tibetan Plateau. Applied Geography 94:147-162.

Hruska T. 2019. Evolving patterns of agricultural frontier expansion in Mexico's Chihuahuan Desert: a political ecology approach. Journal of Land Use Science:1-20. Taylor \& Francis. Jepson W, Brannstrom C, Filippi A. 2010. Access Regimes and Regional Land Change in the Brazilian Cerrado, 1972-2002. Annals of the Association of American Geographers 100:87111.

Kleemann J, Baysal G, Bulley HNN, Fuerst C. 2017. Assessing driving forces of land use and land cover change by a mixed-method approach in north-eastern Ghana, West Africa. Journal of Environmental Management 196:411-442.

Knigge L, Cope M. 2006. Grounded Visualization: Integrating the Analysis of Qualitative and Quantitative Data through Grounded Theory and Visualization. Environment and Planning A: Economy and Space 38:2021-2037.

Kong R, Diepart J-C, Castella J-C, Lestrelin G, Tivet F, Belmain E, Begue A. 2019. Understanding the drivers of deforestation and agricultural transformations in the Northwestern uplands of Cambodia. Applied Geography 102:84-98.

Lawler JA, Lewis DJ, Nelson E, Plantinga AJ, Polasky S, Withey JC, Helmers DP, Martinuzzi S, Pennington D, Radeloff VC. 2014. Projected land-use change impacts on ecosystem services in the United States. Proceedings of the National Academy of Sciences 111:7492-7497.

Liu J et al. 2007. Complexity of Coupled Human and Natural Systems. Science 317:1513-1516.

McGinnis MD, Ostrom E. 2014. Social-ecological system framework: initial changes and continuing challenges. Ecology and Society 19:30. 
Mehring M, Stoll-Kleemann S. 2011. How Effective is the Buffer Zone? Linking Institutional Processes with Satellite Images from a Case Study in the Lore Lindu Forest Biosphere Reserve, Indonesia. Ecology and Society 16:3.

Monroy-Sais S, Castillo A, Garcia-Frapolli E, Ibarra-Manriquez G. 2016. Ecological variability and rule-making processes for forest management institutions: a social-ecological case study in the Jalisco coast, Mexico. International Journal of the Commons 10:1144-1171.

Murgue C, Therond O, Leenhardt D. 2016. Hybridizing local and generic information to model cropping system spatial distribution in an agricultural landscape. Land Use Policy 54:339_ 354.

Newbold T et al. 2015. Global effects of land use on local terrestrial biodiversity. Nature 520:45-50.

Newing H. 2010. Interdisciplinary training in environmental conservation: definitions, progress and future directions. Environmental Conservation 37:410-418.

Nugroho HYSH, van der Veen A, Skidmore AK, Hussin YA. 2018. Expansion of traditional land-use and deforestation: a case study of an adat forest in the Kandilo Subwatershed, East Kalimantan, Indonesia. Journal of Forestry Research 29:495-513.

Olsen W. 2004. Triangulation in social research: Qualitative and quantitative methods can really be mixed. Developments in sociology 20:103-118.

Onwuegbuzie AJ, Hitchcock JH. 2015, August 6. Advanced Mixed Analysis Approaches. Available from https://www.oxfordhandbooks.com/view/10.1093/oxfordhb/9780199933624.001.0001/oxfor dhb-9780199933624-e-19 (accessed April 15, 2020). 
Onwuegbuzie AJ, Leech NL. 2005. On Becoming a Pragmatic Researcher: The Importance of Combining Quantitative and Qualitative Research Methodologies. International Journal of Social Research Methodology 8:375-387.

Östlund U, Kidd L, Wengström Y, Rowa-Dewar N. 2011. Combining qualitative and quantitative research within mixed method research designs: A methodological review. International Journal of Nursing Studies 48:369-383.

Palmer MA. 2012. Socioenvironmental Sustainability and Actionable Science. BioScience 62:56.

Polhill JG, Sutherland L-A, Gotts NM. 2010. Using Qualitative Evidence to Enhance an AgentBased Modelling System for Studying Land Use Change. Jasss-the Journal of Artificial Societies and Social Simulation 13:10.

Prokopy LS, Carlton JS, Haigh T, Lemos MC, Mase AS, Widhalm M. 2017. Useful to usable: Developing usable climate science for agriculture. Climate Risk Management 15:1-7.

Qasim M, Hubacek K, Termansen M. 2013. Underlying and proximate driving causes of land use change in district Swat, Pakistan. Land Use Policy 34:146-157.

Richmond L, Kotowicz D, Hospital J. 2015. Monitoring socioeconomic impacts of Hawai 'i's 2010 bigeye tuna closure: Complexities of local management in a global fishery. Ocean \& Coastal Management 106:87-96.

Sandelowski M, Voils CI, Barroso J. 2006. Defining and designing mixed research synthesis studies. Research in the schools: a nationally refereed journal sponsored by the Mid-South Educational Research Association and the University of Alabama 13:29. NIH Public Access. Scales IR. 2011. Farming at the Forest Frontier: Land Use and Landscape Change in Western Madagascar, 1896-2005. Environment and History 17:499-524. 
Sharma D, Holmes I, Vergara-Asenjo G, Miller WN, Cunampio M, Cunampio RB, Cunampio MB, Potvin C. 2016. A comparison of influences on the landscape of two social-ecological systems. Land Use Policy 57:499-513.

Strang V. 2009. Integrating The Social and Natural Sciences in Environmental Research: A Discussion Paper. Environment, Development and Sustainability 11:1-18.

Sydenstricker-Neto J. 2012. Population and deforestation in the Brazilian Amazon: a mediating perspective and a mixed-method analysis. Population and Environment 34:86-112.

Taylor MJ, Aguilar-Stoen M, Castellanos E, Moran-Taylor MJ, Gerkin K. 2016. International migration, land use change and the environment in Ixcan, Guatemala. Land Use Policy 54:290-301.

Turner II B, Lambin E, Reenberg A. 2007. The emergence of land change science for global environmental change and sustainability. Proceedings of the National Academy of Sciences 104:20666-20671.

Teddlie C, Tashakkori A. 2006. A general typology of research designs featuring mixed methods. Research in the Schools 13:12-28.

Virapongse A, Brooks S, Covelli Metcalf E, Zedalis M, Gosz J, Kliskey A, Alessa L. 2016. A social-ecological systems approach for environmental management. Journal of Environmental Management 178:83-91.

Vogl S. 2019. Integrating and Consolidating Data in Mixed Methods Data Analysis: Examples From Focus Group Data With Children. Journal of Mixed Methods Research 13:536-554. Williams NE, Kramer DB. 2019. Agricultural Biodiversity Maintenance in a Coastal SocioEcological System: the Pearl Lagoon Basin, Nicaragua. Human Ecology 47:111-120. 
Wittman HK, Johnson MS. 2008. Fallow management practices in Guatemala's Western Highlands: Social drivers and biophysical impacts. Land Degradation \& Development 19:178-189.

Wolfram M, Klepper G, Rice M, Schmalzbauer BS, Hackamnn H, Leemans R, Moore H. 2013. Transdisciplinary global change research: the co-creation of knowledge for sustainability. Current Opinion in Environmental Sustainability 5:420-431.

Yin RK. 2006. Mixed methods research: Are the methods genuinely integrated or merely parallel. Research in the Schools 13:41-47.

Yom S. 2015. From Methodology to Practice: Inductive Iteration in Comparative Research. Comparative Political Studies 48:616-644. 


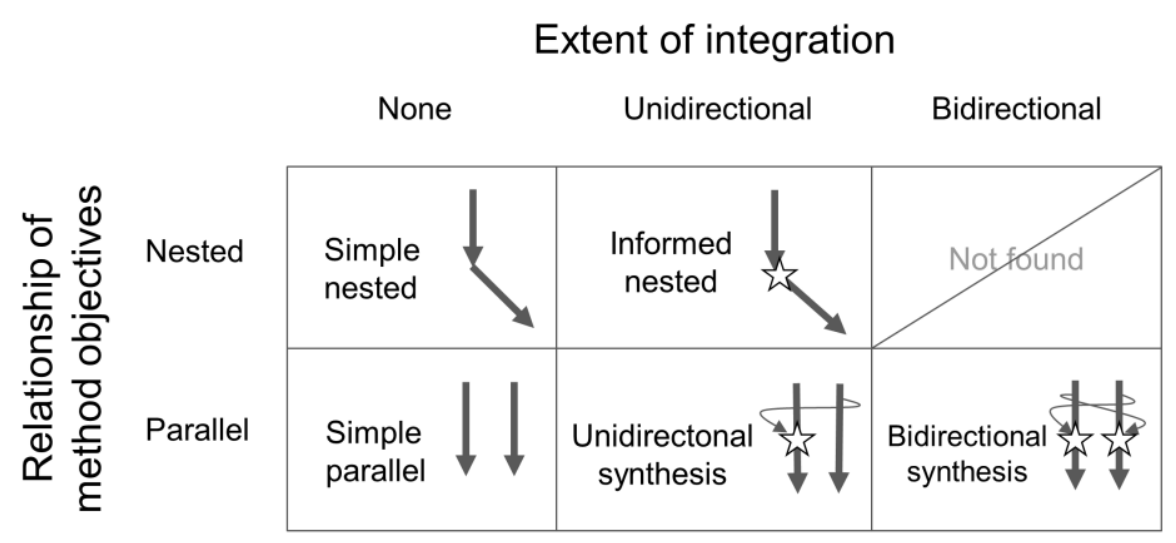

Figure 1: Approaches to mixed methods and their distinguishing characteristics (arrows, different methods; arrow placement, how methods are related in the research process; stars, flow of information (data) between methods, indicating methodological integration). 


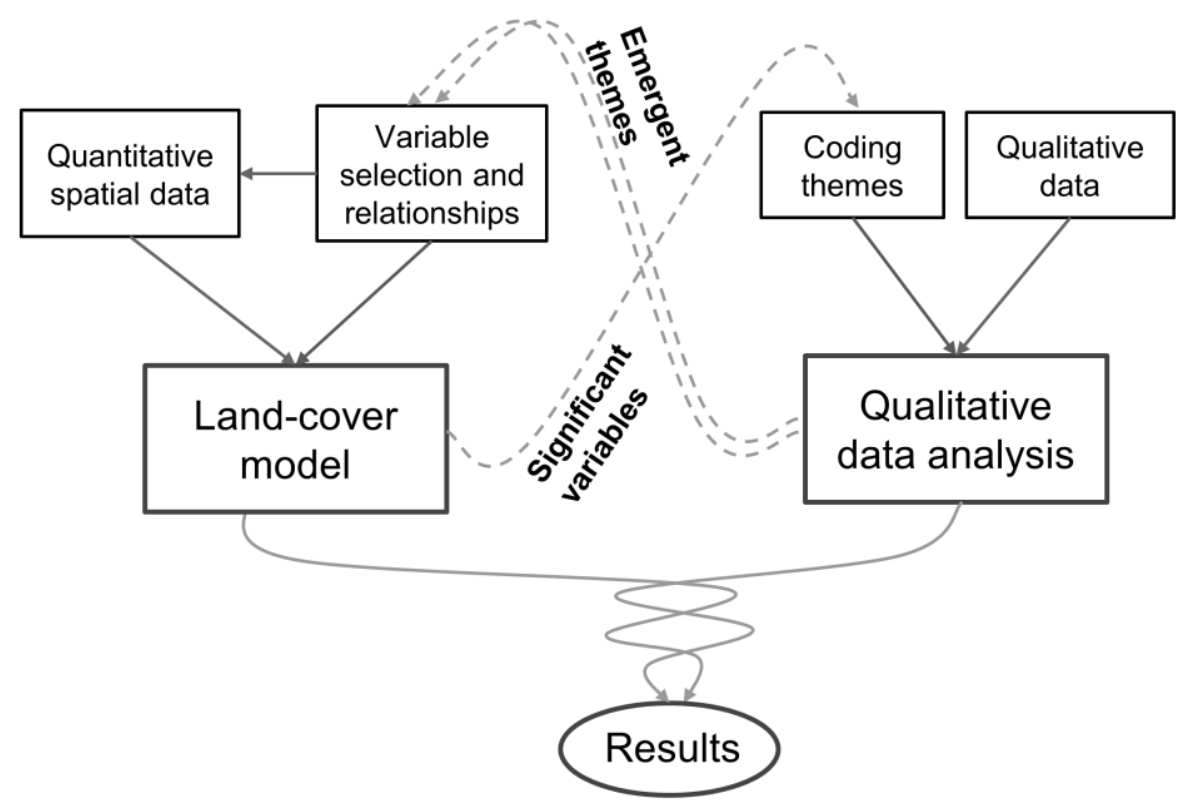

Figure 2: An example of a bidirectionally integrative and iterative research design. 
Table 1: Descriptions and examples of typologies of mixed method, including number of articles in the review from the fields land-change science (LCS) and environmental management (EM).

\begin{tabular}{|c|c|c|c|c|}
\hline \multirow{2}{*}{$\begin{array}{l}\text { Mixed methods } \\
\text { approach }\end{array}$} & \multicolumn{2}{|c|}{ No. of articles } & \multirow[t]{2}{*}{ Description } & \multirow[t]{2}{*}{ Example } \\
\hline & LCS & EM & & \\
\hline Simple nested & 6 & 5 & $\begin{array}{l}\text { Methods address different study } \\
\text { objectives/questions: one method } \\
\text { provides context, justification, or } \\
\text { explanation of the other. No } \\
\text { integration occurs between } \\
\text { methods, and there is sometimes } \\
\text { a clear hierarchy of data. }\end{array}$ & $\begin{array}{l}\text { Quantitative remote sensing and } \\
\text { geospatial analysis show how land- } \\
\text { use has changed (the "what"), and } \\
\text { qualitative analysis describes related } \\
\text { drivers of change (the "why") } \\
\text { (Jepson et al. 2010). }\end{array}$ \\
\hline Informed nested & 1 & 4 & $\begin{array}{l}\text { Methods are nested in structure, } \\
\text { and there is integration from one } \\
\text { method to the other. }\end{array}$ & $\begin{array}{l}\text { Interviews with local people are } \\
\text { used to identify fish spawning areas } \\
\text { and inform sampling areas of } \\
\text { quantitative ecological monitoring } \\
\text { (Adams et al. 2019). }\end{array}$ \\
\hline Simple parallel & 3 & 1 & $\begin{array}{l}\text { Methods address similar } \\
\text { research objectives to } \\
\text { triangulate, compliment, or } \\
\text { further develop understanding of } \\
\text { a single phenomenon. No } \\
\text { integration occurs between } \\
\text { methods, and methods generally } \\
\text { do not have a hierarchy of data. }\end{array}$ & $\begin{array}{l}\text { Quantitative ecological } \\
\text { measurements and qualitative } \\
\text { interview data individually assess } \\
\text { patterns during a } 40 \text { day fishery } \\
\text { closure (Richmond et al. 2015). }\end{array}$ \\
\hline $\begin{array}{l}\text { Unidirectional } \\
\text { synthesis }\end{array}$ & 4 & 4 & $\begin{array}{l}\text { Methods are parallel in structure, } \\
\text { and there is unidirectional } \\
\text { integration between methods, } \\
\text { where data flows from one } \\
\text { method to the other, but not vice } \\
\text { versa. }\end{array}$ & $\begin{array}{l}\text { Quantitative land-use change models } \\
\text { and qualitative interviews, focus } \\
\text { groups, field visits, and discourse } \\
\text { analysis all assess how human } \\
\text { activities affect deforestation, with } \\
\text { qualitative data informing three } \\
\text { model scenarios (Nugroho et al. } \\
\text { 2018). }\end{array}$ \\
\hline $\begin{array}{l}\text { Bidirectional } \\
\text { synthesis }\end{array}$ & 2 & 2 & $\begin{array}{l}\text { Methods are parallel in structure, } \\
\text { and there is bidirectional } \\
\text { integration between methods. } \\
\text { Iteration of methodological }\end{array}$ & $\begin{array}{l}\text { Interview questions are informed by } \\
\text { quantitative model development, and } \\
\text { the model is iteratively updated } \\
\text { based off of interview findings }\end{array}$ \\
\hline
\end{tabular}


integration sometimes occurs. (Polhill et al. 2010). 